\title{
Analiza metod produkcji biowodoru pod kątem wielkości emisji GHG
}

\section{Analysis of biohydrogen production methods in terms of GHG emission value}

\author{
Kamil Berdechowski
}

Instytut Nafty i Gazu - Państwowy Instytut Badawczy

\begin{abstract}
STRESZCZENIE: Jednym z paliw, jakie w przyszłości planuje się wykorzystywać w dużo większym stopniu niż obecnie jest wodór. Wiele wdrażanych technologii ma pozwolić na to, aby bez większych przeszkód stosować ten rodzaj paliwa do pojazdów silnikowych. Jednak już od dawna wodór jest niezbędnym surowcem w wielu instalacjach do produkcji paliw tradycyjnych i używany przede wszystkim do tzw. wodorowych procesów katalitycznych (m.in. hydrokrakingu i hydrorafinacji). Tradycyjna technologia produkcji wodoru polegająca na reformingu parowym gazu ziemnego generuje wysoką emisję GHG w cyklu życia. Przyczyną tego jest wykorzystanie surowca kopalnego, z którego na etapie produkcji powstaje $\mathrm{CO}_{2}$ (traktowany jako emisja z paliwa kopalnego $\mathrm{i}$ wliczany do bilansu emisji GHG). Drugim powodem jest wysoka energochłonność procesu, która przekłada się na dodatkową emisję gazów cieplarnianych generowaną w cyklu życia. Mając na uwadze ten aspekt, celowym jest wykorzystanie alternatywnych sposobów otrzymywania wodoru oraz znanych procesów, ale z wykorzystaniem biomasy odpadowej jako wyjściowego surowca. Procesy takie prowadzą do uzyskania wodoru, który ze względu na pochodzenie surowca z jakiego powstał, traktowany jest jako biopaliwo. Obecne rozwiązania prawne dają możliwość zakwalifikowania biowodoru używanego w wyżej wymienionych procesach rafineryjnych jako biogenny składnik tradycyjnego paliwa. Jednak aby uzyskał on status biopaliwa zaliczonego na poczet realizacji NCW, musi on spełniać wymogi dyrektywy 2009/28/WE (tzw. RED) i ILUC. Kluczowym jest więc udowodnienie, że surowce z których dane biopaliwo wyprodukowano spełniają tzw. kryteria zrównoważonego rozwoju. W artykule opisano metody produkcji wodoru ze szczególnym uwzględnieniem biomasy jako surowca do jego produkcji. W przypadku jej wykorzystania, otrzymany w wyniku jej przeróbki wodór posiada biogenny charakter, a zatem może być potraktowany jako biopaliwo. Jednak zgodnie z obecnymi przepisami, każde biopaliwo, aby zostało zaliczone na poczet realizacji Narodowego Celu Wskaźnikowego (NCW), musi wykazać spełnienie tzw. kryteriów zrównoważonego rozwoju. Jednym z nich jest minimalny poziom ograniczenia emisji gazów cieplarnianych liczony w cyklu życia. Dlatego w artykule przeanalizowano trzy ścieżki produkcyjne, tj. produkcję biowodoru z biogazu, resztek drzewnych oraz surowej gliceryny. Spośród tych trzech najkorzystniejszym wariantem okazał się reforming biogazu, który wykazał ograniczenie emisji GHG na poziomie około 77\%. Dodatkowo, tylko ta ścieżka produkcji spełniła wymagania stawiane biopaliwom otrzymywanym w nowych instalacjach.
\end{abstract}

Słowa kluczowe: biowodór, biopaliwo, reforming, zgazowanie, emisja GHG.

ABSTRACT: One of the fuels which will be used in the future to a much greater extent than currently is hydrogen. Many of the implemented technologies will allow this kind of fuel to drive motor vehicles without major obstacles. However, hydrogen has long been an indispensable raw material for many installations for the production of traditional fuels and used primarily for the so-called hydrogen catalytic processes (including hydrocracking, hydrotreating). Traditional hydrogen production based on natural gas steam reforming, generates high GHG emissions over the life cycle. The reason for this is the use of fossil raw material, from which $\mathrm{CO}_{2}$ is generated at the production stage (treated as emission from fossil fuel and included in the GHG emission balance). The second reason is the high energy consumption of the process, which translates into additional greenhouse gas emissions generated in the life cycle. Given this aspect, it is advisable to use alternative methods of obtaining hydrogen and known processes, but using waste biomass as the starting raw material. Such processes lead to obtaining hydrogen, which due to the origin of the raw material from which it was created, is treated as a biofuel. Current legislation allows the possibility to qualify the biohydrogen used in the abovementioned refinery processes as a biogenic component of traditional fuel. However, according to the current regulations, each biofuel must meet the sustainability criteria. One of them is the minimum level of greenhouse gas emission reduction calculated in the whole life cycle. Therefore, as part of this work, three production paths have been analyzed. The following pathways were analyzed: biohydrogen from biogas, biohydrogen from wood residues and biohydrogen from raw glycerine. Of the three, the most advantageous variant turned out to be biogas reforming, which showed a GHG emission reduction of around 77\%. In addition, only this production path met the requirements for biofuels obtained on new installations.

Key words: biohydrogen, biofuel, reforming, gasification, GHG emissions.

Autor do korespondencji: K. Berdechowski, e-mail.kamil.berdechowski@inig.pl

Artykuł nadesłano do Redakcji 28.12.2018 r. Zatwierdzono do druku 25.03.2019 r. 


\section{Wprowadzenie}

Pozyskiwanie wodoru odbywa się w różnej skali natężenia jego produkcji z zastosowaniem wielu metod: termochemicznych (reforming, piroliza, zgazowanie, rozkład węglowodorów i wody, technologia plazmowa), elektrolizy wody, chemicznych (w różnych reakcjach), biologicznych (różnego rodzaju fermentacje), fotolitycznych i technologii jądrowej. Surowcami do jego produkcji mogą być różne substancje zawierające w swym składzie chemicznym wodór: woda, gaz ziemny, ropa naftowa, węgiel kamienny i brunatny, a także biomasa. Nadaje się do tego również wiele surowców wtórnych: gazy z metod termicznych (surowy gaz syntezowy), gaz syntezowy (syngaz; wodór + tlenek węgla), węglowodory, metanol i wyższe alkohole, eter dwumetylowy (DME), olej popirolityczny, surowce rafineryjne, produkty fermentacji, a także odpady przemysłowe (np. tworzywa sztuczne). Dotychczas około 95\% gazu syntezowego, z którego produkuje się wodór otrzymuje się z przetwórstwa termochemicznego surowców kopalnych, głównie metodami reformingu z gazu ziemnego i w mniejszym stopniu metodami zgazowania. Jednakże mając na uwadze ograniczone zasoby surowców kopalnych oraz nowe trendy technologiczne $\mathrm{i}$ aspekt polityczny, wzrasta rola biomasy jako jednego z istotnych nośników energii (Warowny, 2008).

Wielu autorów opisuje wyżej wymienione procesy - zarówno te wykorzystujące surowce kopalne (Wender, 1996; Higman et al., 2003; Warowny et al., 2006; Demusiak, 2012), jak i biomasę (Lu et al., 2006; Ni et al., 2006; Chmielniak et al., 2003). Produkcja wodoru w przemianach termochemicznych wymaga oprócz substratów chemicznych dostarczenia energii. Do bezpośredniego pozyskania wodoru z surowego gazu syntezowego z procesów reformingu, zgazowania i pirolizy stosuje się metodę adsorpcji zmiennociśnieniowej PSA (Pressure Swing Adsorption) albo metodę pośrednią selektywnego utleniania tlenku węgla $\mathrm{z}$ surowego gazu syntezowego i następnie oczyszczanie metodą PSA, celem uzyskania wodoru o czystości 99,9\% (Warowny, 2008).

\section{Analiza teoretyczna}

Wodór może być produkowany z biomasy. Biorąc pod uwagę obowiązek zwiększania udziału biopaliw oraz korzystniejsze rozliczanie biopaliw w przypadku ich odpadowego charakteru, najkorzystniejszym wydaje się produkcja wodoru z biogennych surowców odpadowych. Załącznik IX (część A i B) do dyrektywy ILUC wymienia surowce, które w wyniku przetwarzania na kolejnych etapach prowadzą do biowodoru. Mogą to być między innymi odpady piekarnicze (do produkcji etanolu przetwarzanego do wodoru w procesie reformingu), gliceryna surowa (po produkcji FAME kierowana do piroreformingu), resztki drzewne (poddawane zgazowaniu a następnie reformingowi) oraz biogaz (kierowany do reformingu parowego).

Zgazowanie biomasy jest przeprowadzane przy użyciu reaktora ze złożem fluidalnym, gdzie następuje uzyskanie gazowych produktów, a z zastosowaniem aparatury towarzyszącej odzyskanie wodoru. W celu uzyskania wodoru można poddawać procesowi reformingu parowego również olej otrzymany w wyniku pirolizy biomasy, który jest mieszaniną kwasów karboksylowych, alkoholi, aldehydów i ketonów. Decydującym czynnikiem w procesie reformingu parowego jest stosunek pary wodnej do węgla zawartego w oleju. W temperaturze $800^{\circ} \mathrm{C}$ stosując katalizator $\mathrm{CeZrO}_{2} \mathrm{z}$ dodatkiem Pt, Rt w reformingu oleju pirolitycznego z drewna można uzyskać nawet 70\% wodoru. Bardzo ważne są mieszane metody produkcji wodoru z biomasy. Jedną z nich jest metoda łącząca fluidalne zgazowanie biomasy i reformingu surowego gazu otrzymanego w procesie jej pirolizy. Szybka piroliza suchej biomasy w złożu fluidalnym zachodzi w temperaturze $530^{\circ} \mathrm{C}$. Bioolej kondensuje się z przeznaczeniem do dalszej przeróbki. Karbonizat $i$ gazy popirolityczne spala on natomiast $w$ celu ogrzewania reaktora. Bioolej będący produktem wielu niezależnych procesów pirolizy jest poddawany w reaktorze zbiorczym ekstrakcyjnemu rozdzieleniu na frakcję ligninową i węglowodanową oraz katalitycznemu procesowi reformingu parowego $\mathrm{w}$ temperaturze $850^{\circ} \mathrm{C}$ pod ciśnieniem $3,5 \mathrm{MPa}$. W dwóch kolejnych reaktorach układu (dla warunków $370^{\circ} \mathrm{C}, 3 \mathrm{MPa}$ oraz $200^{\circ} \mathrm{C}$, 2,5 MPa) z gazu syntezowego produkuje się gaz bogaty w wodór poprzez przesunięcie stanu równowagi, stosownie do homogenicznej reakcji gazu wodnego. Ostatecznie czysty wodór otrzymuje się po procesie oczyszczania metodą PSA.

Wodór można także pozyskiwać metodami reformingu używając biogazu jako surowca. Do tego celu nadaje się doskonale reforming parowy. Natomiast biogaz używany w reformingu powstaje w biogazowniach rolniczych, oczyszczalniach ścieków lub na wysypiskach śmieci w beztlenowej fermentacji z surowców organicznych.

Kolejnym przykładem surowca kwalifikowanego jako pozostałość i możliwego do wykorzystania w produkcji wodoru jest surowa gliceryna jako produkt uboczny wytwarzania FAME. W przypadku, gdy FAME jest produkowane $\mathrm{z}$ oleju odpadowego to powstający produkt uboczny procesu, czyli gliceryna ma również status produktu/surowca odpadowego. W miejscowości Leuna (Niemcy) uruchomiono fabrykę demonstracyjną, której zdolność produkcyjna wodoru wynosi 4,5 kg/h (Tamhankar, 2012). Glicerol z instalacji transestryfikacji kierowany jest do połączonego procesu piroreformingu. Glicerol jako produkt uboczny wytwarzania biodiesla (około $10 \%$ w stosunku do produktu głównego - FAME), powstaje w dużych ilościach ze względu na jego duże zapotrzebowanie. 


\section{Część doświadczalna}

W niniejszej pracy przeprowadzono kalkulacje emisji GHG w cyklu życia dla trzech możliwych ścieżek produkcji biowodoru, tj.: (i) wodoru z reformingu parowego biometanu uzyskiwanego w biogazowni (instalacje połączone), (ii) wodoru z procesu zgazowania i pirolizy resztek drzewnych oraz (iii) wodoru z piroreformingu gliceryny surowej.

Dane do sporządzenia bilansów materiałowych i energetycznych wyżej wymienionych procesów, które były podstawą wyliczeń emisji GHG zaczerpnięto z opisu poszczególnych technologii (Wulf et al., 2013). Wskaźniki emisji GHG przyjęte do obliczeń wraz z ich źródłami umieszczono w tabeli 5. Jako jednostkę funkcjonalną przyjęto $\mathrm{gCO}_{2} \mathrm{eq} / \mathrm{MJ}$ energii zawartej w biowodorze.

Do wykonania obliczeń niezbędne były również dane na temat wskaźników emisji GHG użytych mediów oraz

Tabela 1. Dane wejściowe do obliczeń - bilans strumieni wejściowych i wyjściowych - biogazownia

Table 1. Input data for calculations - balance of input and output streams - biogas plant

\begin{tabular}{|c|c|}
\hline \multicolumn{2}{|c|}{ Surowiec/medium } \\
\hline Nazwa & Ilość \\
\hline \hline Odpady biologiczne & $576000000 \mathrm{~kg}$ \\
\hline Energia elektryczna & $15696000 \mathrm{MJ}$ \\
\hline Woda & $0,2311 \mathrm{~m}^{3}$ \\
\hline $\mathrm{FeCl}_{3}$ & $12875 \mathrm{~kg}$ \\
\hline Glikol trietylenowy & $281,8 \mathrm{~kg}$ \\
\hline \multicolumn{2}{|c|}{ Uzysk } \\
\hline \hline Nazwa & Ilość \\
\hline Biometan & $26496000 \mathrm{~kg}$ \\
& $(1247961600 \mathrm{MJ})$ \\
\hline
\end{tabular}

Tabela 2. Dane wejściowe do obliczeń - bilans strumieni wejściowych i wyjściowych - reforming

Table 2. Input data for calculations - balance of input and output streams - reforming

\begin{tabular}{|c|c|}
\hline \multicolumn{2}{|c|}{ Surowiec/medium } \\
\hline Nazwa & Ilość \\
\hline \hline Biometan & $\begin{array}{c}26496000 \mathrm{~kg} \\
(1247961600 \mathrm{MJ})\end{array}$ \\
\hline Energia elektryczna ( z sieci) & $3396556,8 \mathrm{MJ}$ \\
\hline Ciepło (ze spalania biogazu) & $946183680 \mathrm{MJ}$ \\
\hline Woda & $82892,16 \mathrm{~m}^{3}$ \\
\hline \multicolumn{2}{|c|}{ Uzysk } \\
\hline Nazwa & Ilość \\
\hline \hline Biowodór + wodór & $673920000 \mathrm{MJ}$ \\
\hline
\end{tabular}

chemikaliów. Użyte wartości wraz z ich źródłami przedstawione zostały poniżej.

Tabela 3. Dane wejściowe do obliczeń - bilans strumieni wejściowych i wyjściowych - zgazowanie resztek drzewnych

Table 3. Input data for calculations - balance of input and output streams - gasification of wood residues

\begin{tabular}{|c|c|}
\hline \multicolumn{2}{|c|}{ Surowiec/medium } \\
\hline Nazwa & Ilośćć \\
\hline \hline Resztki drzewne & $37435500 \mathrm{~kg}$ \\
\hline Energia elektryczna ( z sieci) & $145275120 \mathrm{MJ}$ \\
\hline Woda & $11167,2 \mathrm{~m} 3$ \\
\hline Azot & $827388 \mathrm{~kg}$ \\
\hline & \\
\hline Nazwa & Ilość \\
\hline \hline Biowodór + wodór & $253800000 \mathrm{MJ}$ \\
\hline
\end{tabular}

Tabela 4. Dane wejściowe do obliczeń - bilans strumieni wejściowych i wyjściowych - piroreforming gliceryny

Table 4. Input data for calculations - balance of input and output streams - piroreforming of glycerine

\begin{tabular}{|c|c|}
\hline \multicolumn{2}{|c|}{ Surowiec/medium } \\
\hline Nazwa & ilość \\
\hline \hline Gliceryna surowa & $22464000 \mathrm{~kg}$ \\
\hline $\begin{array}{c}\text { Para technologiczna (zużycie } \\
\text { gazu ziemnego z sieci) }\end{array}$ & $178848000 \mathrm{MJ}$ \\
\hline Energia elektryczna ( z sieci) & $432034560 \mathrm{MJ}$ \\
\hline Woda & $178848 \mathrm{~m}^{3}$ \\
\hline \multicolumn{2}{|c|}{ Uzysk } \\
\hline Nazwa & Ilość \\
\hline Biowodór + wodór & $259200000 \mathrm{MJ}$ \\
\hline
\end{tabular}

Tabela 5. Wskaźniki emisji GHG użyte do obliczeń

Table 5. GHG emission factors used for calculations

\begin{tabular}{|c|c|c|}
\hline Surowiec/medium & $\begin{array}{c}\text { Wskaźnik emisji } \\
\text { GHG }\end{array}$ & Źródło \\
\hline $\begin{array}{l}\text { Odpady biologiczne } \\
\text { (w biogazowni) }\end{array}$ & 0 & \multirow{3}{*}{ 2009/28/WE } \\
\hline Resztki drzewne & 0 & \\
\hline Gliceryna surowa & 0 & \\
\hline $\begin{array}{l}\text { Biometan otrzymany } \\
\text { w biogazowni }\end{array}$ & $1,63 \mathrm{CO}_{2 \mathrm{eq}} / \mathrm{MJ}$ & $\begin{array}{c}\text { Na podstawie } \\
\text { danych bilansowych } \\
\text { z tabeli } 1 .\end{array}$ \\
\hline Ciepło & $56,2 \mathrm{~g} \mathrm{CO}_{2 \mathrm{eq}} / \mathrm{MJ}$ & (Raport JRC 2017) \\
\hline Energia elektryczna & $129,19 \mathrm{~g} \mathrm{CO}_{2 \mathrm{eq}} / \mathrm{MJ}$ & (Biograce 2015) \\
\hline Woda & $320 \mathrm{~g} \mathrm{CO}_{2 \mathrm{eq}} / \mathrm{m}^{3}$ & \multirow{3}{*}{$\begin{array}{l}\text { (Raport Veolia } \\
\text { Water 2011) }\end{array}$} \\
\hline Azot & $430 \mathrm{~g} \mathrm{CO}_{2 \mathrm{eq}} / \mathrm{kg}$ & \\
\hline $\mathrm{FeCl}_{3}$ & $180 \mathrm{~g} \mathrm{CO}_{2 \mathrm{eq}} / \mathrm{kg}$ & \\
\hline
\end{tabular}




\section{Metodyka}

Zgodnie z wytycznymi podanymi w załączniku $\mathrm{V}$ do dyrektywy 2009/28/WE (dyrektywa 2015/1513) emisję gazów cieplarnianych w cyklu życia biopaliw (E) obliczono zgodnie z następującym wzorem:

$$
E=e_{e c}+e_{l}+e_{p}+e_{t d}+e_{u}-e_{s c a}-e_{c c s}-e_{c c r}-e_{e e}
$$

Emisja GHG dla poszczególnych operacji jednostkowych została wyznaczona na podstawie poniższego równania:

$$
C_{x}=\varepsilon_{x} \cdot F_{e x}
$$

gdzie:

$C_{x}$ - jest wyrażoną w jednostkach masy ilością gazów cieplarnianych $\left(\mathrm{CO}_{2 \mathrm{eq}}\right) \mathrm{w}$ zadanym okresie czasu w wyniku zużycia energii,

$\varepsilon_{x}$ - jest ilością surowców lub energii zużytych w zadanym okresie czasu,

$F_{e x}$ - jest wskaźnikiem emisji GHG dla danego surowca lub paliwa, uwzględniającym jego wyprodukowanie i zużycie końcowe (wyrażony w jednostce $\mathrm{CO}_{2 \mathrm{eq}}$ /jednostkę masy lub energii).

Przy przeprowadzaniu obliczeń przyjęto dodatkowo następujące założenia i wykluczenia: $(i)$ obliczenia prowadzono dla przypadków, gdy surowcami wyjściowymi były surowce zaliczane do grupy odpadów i pozostałości, (ii) pominięto emisję związaną z produkcją i utylizacją katalizatorów do procesu, (iii) nie uwzględniono emisji związanej z produkcją maszyn i urządzeń oraz (iv) przyjęto, że instalacja reformingu parowego znajduje się w pobliżu biogazowni i ciepło dla instalacji pochodzi ze spalania biogazu.

\section{Wyniki oraz ich dyskusja}

Na podstawie danych zawartych w tabelach 1-5 oszacowano całkowitą emisję w procesie, a następnie po uwzględnieniu energii zawartej w produktach poszczególnych procesów oszacowano wskaźniki emisji wytworzonego wodoru.

Przedstawione wyniki obliczeń wskazują, że spośród trzech przeanalizowanych metod otrzymywania wodoru, najwyższy poziom ograniczenia emisji wykazała ścieżka bazująca na biogazowni, z której otrzymywany biometan jest kierowany do procesu reformingu parowego. Duży wpływ na wynik ma w tym przypadku ,połączenie” dwóch instalacji, tj. biogazowni i reformingu. Dzięki temu biogaz pochodzenia odpadowego i niskim wskaźniku emisji GHG, z jednej strony, stanowi niskoemisyjny surowiec oraz dodatkowo niskoemisyjne źródło energii do produkcji ciepła niezbędnego w

Tabela 6. Składowe emisji GHG w cyklu życia i ich omówienie

\begin{tabular}{|c|c|}
\hline Nazwa składowej & Komentarz \\
\hline $\begin{array}{l}e_{e c} \\
\text { - emisja spowodowana wydobyciem lub uprawą surowców }\end{array}$ & $\begin{array}{l}\text { - analizie poddano wyłącznie surowce o statusie odpadu lub pozosta- } \\
\text { łości. W związku z tym wartość składowej wynosi zero }\end{array}$ \\
\hline $\begin{array}{l}e_{l} \\
\text { - emisja w ujęciu rocznym spowodowana zmianami ilości pier- } \\
\text { wiastka węgla w związku ze zmianą sposobu użytkowania gruntu }\end{array}$ & - w przypadku analizowanych surowców wartość składowej wynosi zero \\
\hline $\begin{array}{l}e_{p} \\
\text { - emisja spowodowana procesami technologicznymi }\end{array}$ & - $\quad$ składowa liczona w dalszej części pracy \\
\hline $\begin{array}{l}e_{t d} \\
\text { - emisja spowodowana transportem i dystrybucją }\end{array}$ & $\begin{array}{l}\text { - składowa pominięta w obliczeniach, ze względu na to, że celem było } \\
\text { porównanie samych procesów technologicznych. Transport i dystry- } \\
\text { bucja dla tych ścieżek nie różnią się natomiast znacząco od siebie, } \\
\text { co do wielkości emisji GHG }\end{array}$ \\
\hline $\begin{array}{l}e_{u} \\
\cdot{ }^{\prime} \text { emisja spowodowana stosowanym paliwem }\end{array}$ & - dla paliw z biomasy wartość wynosi zero \\
\hline $\begin{array}{l}e_{s c a} \\
\text { - wartość ograniczenia emisji spowodowanego akumulacją pier- } \\
\text { wiastka węgla w glebie dzięki lepszej gospodarce rolnej }\end{array}$ & - składowa równa zero (brak ograniczenia) - technika nie stosowana \\
\hline $\begin{array}{l}e_{c c s} \\
\text { - } \text { ograniczenie emisji spowodowanej wychwytywaniem ditlenku } \\
\text { węgla i składowaniem w głębokich strukturach geologicznych }\end{array}$ & - składowa równa zero (brak ograniczenia) - technika nie stosowana \\
\hline $\begin{array}{l}e_{c c r} \\
\text { - } \text { ograniczanie emisji spowodowane wychwytywaniem ditlenku } \\
\text { węgla i jego zastępowaniem }\end{array}$ & - składowa równa zero (brak ograniczenia) - technika nie stosowana \\
\hline $\begin{array}{l}e_{e e} \\
\text { - }{ } \text { ograniczenie emisji dzięki zwiększonej produkcji energii elek- } \\
\text { trycznej w wyniku kogeneracji }\end{array}$ & - składowa równa zero (brak ograniczenia) - technika nie stosowana \\
\hline
\end{tabular}

Table 6. Components of GHG emissions in the life cycle and their discussion 
Tabela 7. Całkowita emisja GHG dla danego procesu

Table 7. Total GHG emission for a given process

\begin{tabular}{|l|c|c|}
\hline \multirow{2}{*}{\multicolumn{1}{|c|}{ Nazwa produktu/ ścieżki produkcyjnej }} & $\begin{array}{c}\text { Całkowita emisja w procesie, } \\
\text { GHG }\end{array}$ & $\begin{array}{c}\text { Ilość energii zawarta } \\
\text { w produkcie (wodorze) }\end{array}$ \\
\cline { 2 - 3 } & {$\left[\right.$ [g CO $_{\text {2eq }}$ ] } & [MJ] \\
\hline Wodór z biometanu otrzymywanego w biogazowni & 4036117141 & 673920000 \\
\hline Wodór ze zgazowania resztek drzewnych & 19127443097 & 253800000 \\
\hline Wodór z piroreformingu gliceryny surowej & 65923033766 & 259200000 \\
\hline
\end{tabular}

Tabela 8. Wskaźniki emisji GHG wyznaczone dla analizowanych procesów

Table 8. GHG emission factors determined for the analyzed processes

\begin{tabular}{|c|c|c|}
\hline Nazwa produktu/ ścieżki produkcyjnej & $\begin{array}{l}\text { Wskaźnik emisji GHG, } \\
\text { g CO}_{2 \mathrm{eq}} / \mathrm{MJ} \text { wodoru }\end{array}$ & $\begin{array}{c}\text { Procent ograniczenie emisji } \\
\text { względem odpowiednika } \\
\text { kopalnego }\left(83,8 \text { g CO } \mathrm{CO}_{2 \mathrm{q}} / \mathrm{MJ}\right)\end{array}$ \\
\hline Wodór z biometanu otrzymywanego w biogazowni & 5,99 & $77,81 \%$ \\
\hline Wodór ze zgazowania resztek drzewnych & 75,36 & $8,43 \%$ \\
\hline Wodór z piroreformingu gliceryny surowej & 254,33 & brak ograniczenia \\
\hline
\end{tabular}

reformingu. Wodór otrzymany z resztek drzewnych wykazał się bardzo małym ograniczeniem emisji GHG. Wodór otrzymany z gliceryny surowej wygenerował natomiast wyższą emisję niż tzw. odpowiednik kopalny. Tak więc z punktu widzenia rynku paliwowego, dla którego kluczowym jest osiąganie przez biopaliwa minimalnego poziomu ograniczenia emisji GHG 2015/1513 (wg dyrektywy 2015/1513 jest to przynajmniej $60 \%$ dla instalacji, które rozpoczęły pracę po dniu 5 października 2015 r.), tylko wodór uzyskany z biometanu spełnił te wymagania.

\section{Wnioski końcowe}

1. W ramach niniejszej pracy opisano metody produkcji wodoru ze szczególnym uwzględnieniem biomasy jako surowca do jego produkcji. W przypadku jej wykorzystania, otrzymany w ten sposób wodór ma biogenny charakter, a zatem może być potraktowany jako biopaliwo.

2. Zgodnie z obecnymi przepisami, każde biopaliwo, aby zostało zaliczone na poczet realizacji Narodowego Celu Wskaźnikowego, musi wykazać spełnienie tzw. kryteriów zrównoważonego rozwoju. Jednym z nich jest minimalny poziom ograniczenia emisji gazów cieplarnianych liczony w cyklu życia. Obecne wymogi to w zależności od wieku instalacji produkcyjnej 50\% lub 60\% (licząc względem odpowiednika kopalnego).

3. Ze względu na to, że niezależnie od wyboru procesu produkcji wodoru, każdy z nich jest bardzo energochłonny, celowym jest więc minimalizowanie innych składowych emisji GHG, w szczególności składowej wnoszonej z surowcami. Racjonalnym rozwiązaniem jest w tym przypadku stosowanie surowców odpadowych, które zgodnie z ogólnie przyjętą metodyką są zeroemisyjne.

4. W ramach niniejszej pracy przeanalizowano trzy ścieżki produkcyjne, tj. sposoby otrzymywania biowodoru z biogazu, resztek drzewnych oraz surowej gliceryny. Spośród tych trzech najkorzystniejszym wariantem okazał się reforming biogazu, który wykazał ograniczenie emisji GHG na poziomie około $77 \%$. Na tak dobry wynik wpłynął fakt, że w obliczeniach przyjęto m.in., że proces reformingu zasilany jest ciepłem pochodzącym również z biogazu (instalacja reformingu w pobliżu biogazowni).

5. Pozostałe dwa procesy cechowała dużo wyższa energochłonność - głównie zapotrzebowanie na energię elektryczną, co przełożyło się na wysoką całkowitą emisję. W konsekwencji tylko ścieżka otrzymywania biowodoru z biometanu uzyskanego z odpadów spełniła stawiane wymagania dotyczące minimalnego progu ograniczenia emisji GHG dla tzw. nowych instalacji.

Artykuł powstał na podstawie pracy statutowej pt.: Analiza metod produkcji biowodoru pod katem wielkości emisji GHG - praca INiG - PIB na zlecenie MNiSW; nr zlecenia 0089/TP/18, nr archiwalny DK-4100-81/18.

\section{Literatura}

Biograce, The BioGrace GHG calculation tool: a recognised voluntary scheme. https://www.biograce.net/content/ghgcalculationtools/recognisedtool/ (dostęp: październik 2018).

Chmielniak T., Sciążko M., 2003. Co-gasification of biomass and coal for methanol synthesis. Applied Energy, 74: 393-403. DOI: 10.1016/s0306-2619(02)00184-8.

Demusiak G., 2012. Otrzymywanie paliwa wodorowego metodą 
reformowania gazu ziemnego dla ogniw paliwowych małej mocy. Nafta-Gaz, 10: 661-673.

Higman C., van der Burgt M., 2003. Gasification. Burlington: Elsevier. ISBN: 978-0-7506-8528-3.

Lu. Y.J., Guo L.J., Ji C.M., Zhang X.M., Xao X.H., Yan Q., 2006. Hydrogen production by biomass gasification in supercritical water: A parametric study. International Journal of Hydrogen Energy, 31(7): 822-831. DOI: 10.1016/j.ijhydene.2005.08.011.

Ni M., Leung D.Y.C., Leung M.K.H., Sumathy K., 2006. An overview of hydrogen production from biomass. Fuel Processing Technology, 87(5): 461-472. DOI: 10.1016/j.fuproc.2005.11.003.

Raport JRC, 2017. Definition of input data to assess GHG default emissions from biofuels in EU legislation, https://ec.europa.eu/ jrc/en/publication/eur-scientific-and-technical-research-reports/ definition-input-data-assess-ghg-default-emissions-biofuels-eulegislation-version-1c-july (dostęp: październik 2018).

Tamhankar S., 2012. Green hydrogen by pyroreforming of glycerol. In: Hydrogen Systems: Enabling Energy Solutions. World Hydrogen Energy Conference, Toronto, 3-7.06.2012.

Warowny W., 2008. Podstawowe technologie termochemicznego pozyskiwania wodoru. Gaz, Woda i Technika Sanitarna, 5: 8-14. ISSN: 0016-5352.

Warowny W., Kwiecień K., 2006. Reforming gazu ziemnego ditlenkiem węgla. Nafta-Gaz, 12: 680-691.

Wender I.: Reactions of synthesis gas, Fuel Processing Technology, 1996,48,189-297, DOI: 10.1016/s0378-3820(96)01048-x;

Winnipeg Sewage Treatment Program. South end Plant. Process Selection Report. https:/www.winnipeg.ca/finance/findata/
matmgt/documents//2012/682-2012//682-2012_Appendix_HWSTP_South_End_Plant_Process_Selection_Report/PSR rev\%20final.pdf (dostęp: październik 2018).

Wulf C., Kaltschmitt M., 2013: Life cycle assessment of biohydrogen production as a transportation fuel in Germany. Bioresource Technology, 150: 466-475. DOI: 10.1016/j.biortech.2013.08.127.

\section{Akty prawne i normatywne}

Dyrektywa Parlamentu Europejskiego i Rady (UE) 2015/1513 z dnia 9 września 2015 r. zmieniająca dyrektywę 98/70/WE odnoszącą się do jakości benzyny i olejów napędowych oraz zmieniająca dyrektywę 2009/28/WE w sprawie promowania stosowania energii ze źródeł odnawialnych.

Dyrektywa Parlamentu Europejskiego i Rady 2009/28/WE z dnia 23 kwietnia 2009 r. w sprawie promowania stosowania energii ze źródeł odnawialnych zmieniająca i w następstwie uchylająca dyrektywy 2001/77/WE oraz 2003/30/WE.

\section{OFERTA}

\section{ZAKŁAD PALIW I PROCESÓW KATALITYCZNYCH}

Zakres działania:

- $\quad$ opracowywanie, rozwijanie i wdrażanie technologii produkcji LPG, benzyn silnikowych, paliw lotniczych, olejów napędowych, biopaliw I i II generacji oraz olejów opałowych, prowadzenie nadzoru technologicznego nad opracowanymi i wdrożonymi technologiami;

- ocena i atestacja komponentów paliwowych, w tym biokomponentów I i II generacji oraz komponentów ze źródeł alternatywnych;

- opracowywanie technologii uszlachetniania paliw i biopaliw silnikowych oraz olejów opałowych i rozpuszczalników, dobór odpowiednich dodatków uszlachetniających;

- $\quad$ wykonywanie badań i ekspertyz dotyczących jakości paliw i biopaliw silnikowych, olejów opałowych, rozpuszczalników i ich komponentów oraz ocena zgodności ze specyfikacją;

- $\quad$ ocena skażenia mikrobiologicznego paliw w systemie produkcji i dystrybucji;

- ocena właściwości niskotemperaturowych olejów napędowych i opałowych;

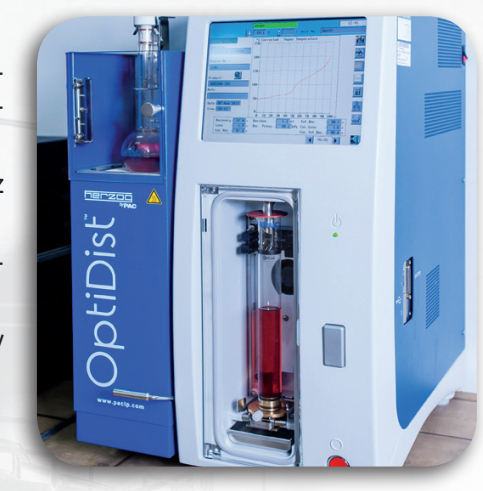

- badania stabilności pozostałościowych olejów opałowych i kompatybilności ich komponentów;

- opracowywanie, rozwijanie i wdrażanie nowych wodorowych procesów katalitycznych, ocena testowa i procesowa katalizatorów stosowanych w przemyśle rafineryjnym w procesach zeoformingu, hydroodsiarczania, hydrorafinacji i katalitycznego odparafinowania;

- ocena oddziaływania na środowisko paliw, biopaliw i innych produktów pochodzących z przemysłu rafineryjnego i petrochemicznego w oparciu o analizę cyklu życia produktu (LCA).

Kierownik: dr inż. Jan Lubowicz

Adres: ul. Łukasiewicza 1, 31-429 Kraków

Telefon: 126177550

Faks: 126177522

E-mail: jan.lubowicz@inig.pl 